\title{
Increased expression of EphA2 correlates with adverse outcome in primary and recurrent glioblastoma multiforme patients
}

\author{
LIN-FANG WANG ${ }^{1,4}$, EMMANOUIL FOKAS $^{1}$, MICHAEL BIEKER ${ }^{1}$, FRANK ROSE ${ }^{1}$, PETER REXIN ${ }^{2}$, \\ YUAN ZHU ${ }^{3}$, AXEL PAGENSTECHER ${ }^{2}$, RITA ENGENHART-CABILLIC ${ }^{1}$ and HAN-XIANG AN ${ }^{1}$ \\ Departments of ${ }^{1}$ Radiation Therapy and Radiooncology, ${ }^{2}$ Neuropathology and ${ }^{3}$ Neurosurgery, Philipps-University \\ Marburg, Germany; ${ }^{4}$ Department of Emergency Surgery, Union Hospital, Tongji Medical College, \\ Huazhong University of Science and Technology, Wuhan, P.R. China
}

Received August 16, 2007; Accepted September 27, 2007

\begin{abstract}
Glioblastoma multiforme (GBM) is the most aggressive form of brain tumor characterized by excessive angiogenesis. The dismal prognosis of patients with GBM warrants the development of new targeting therapies based on novel molecular markers. The EphA2 receptor tyrosine kinase plays a pivotal role in tumor angiogenesis and an increased expression in glioma patients has recently been reported. In this study, we investigated the expression of EphA2 in human normal brain, primary and recurrent GBM and correlated it with clinical pathological parameters and patient's outcome. In addition, intratumor microvascular density was quantified by immunostaining for the endothelial cell marker, von Willebrand factor. A different intensity of the membranous and cytoplastic expression of EphA2 was observed in the 40 primary and recurrent samples of GBM analyzed but not in the normal brain. A high level expression of EphA2 was demonstrated in $24(60 \%)$ of the primary and recurrent GBM analyzed. The increased expression of the EphA2 protein was significantly associated with the adverse outcome of GBM patients $(\mathrm{p}<0.01$ for overall survival). The data presented in this study define the expression pattern of EphA2 in both primary and recurrent glioblastoma and suggest an important role of EphA2 in the pathogenesis of GBM. The EphA2 may be used as a surrogate marker to screen patients for tyrosine kinase inhibitor therapy.
\end{abstract}

\section{Introduction}

Gliomas of astrocytic, oligodendroglial and ependymal origins represent more than $70 \%$ of all primary brain tumors (1). Primary tumors of brain account for around $2 \%$ of primary

Correspondence to: Dr Han-Xiang An, Department of Radiation Therapy and Radiooncology, Philipps-University Marburg, Baldingerstr., D-35043 Marburg, Germany

E-mail: an@med.uni-marburg.de

Key words: EphA2, expression, glioblastoma multiforme, microvessel density, survival tumors but are responsible for $7 \%$ of the years of life lost to cancer before the age of 70 . The incidence of brain tumors worldwide is about 7 in 100,000 per year (2). Glioblastoma multiforme (GBM), the most devastating type of glioma, is the most common primary brain tumor in adults and represents a significant source of cancer-related death. Glioblastoma usually recurs independently of the type of treatment(s) viz surgical resection of the tumor followed by radiation and/or chemotherapy (2). The poor prognosis of patients with GBM (median survival ranging from 9 to 12 months, 5-year survival rate close to $0 \%$ ) mandates the exploration of novel molecular mechanisms that may contribute to the pathogenesis of this disease and its resistance to therapy with the purpose of therapeutic targeting $(2,3)$.

The Eph receptors (erythropoietin-producing human hepatocellular carcinoma) have been intensely studied since their discovery nearly two decades ago. Eph receptor tyrosine kinases (RTK) represent the largest family of protein-tyrosine kinases consisting of 16 members. Eph receptors and their corresponding ephrin ligands are classified into an A and B subfamily based on the distinct structural properties of the ephrin ligands $(4,5)$. EphrinA ligands are glycosylphosphatidylinositol (GPI)-anchored peripheral membrane molecules. In contrast, ephrinB ligands are transmembrane molecules whose cytoplasmic domain is capable of engaging in various signaling activities (4). In contrast to other RTKs, where the ligand functions as a soluble molecule, these Eph-RTKs are unique in that their ligands are attached to the cell membrane and therefore interaction necessitates direct cell to cell contact (3). Moreover, these RTKs have the ability to induce both forward and reverse (bi-directional) signaling between adjacent interacting cells (5). Most of the Eph receptors bind to their specific ephrin ligands, even though some ephrins seem to be promiscuous, interacting with more than one receptor (6). Eph receptor signaling has been implicated in many biological processes such as axon guidance and fasciculation, tissue border formation, neuronal targeting and angiogenesis during embryonic development $(7,8)$. Recent studies demonstrated that Ephs and ephrins are frequently overexpressed in a variety of cancers and tumor cell lines $(4,5)$.

Various studies have identified the involvement of the Eph-RTKs in several pathogenetic processes in the nervous 
system. EphB2 and ephrinB2 signaling was found to participate in the glial scarring process after a spinal cord trauma (9). The phosphorylation ratio of R-Ras was closely linked to the phosphorylation ratio of EphB2 in glioblastoma tissues (10). Additionally, the phosphorylation ratio of EphB2 was identified as an important mechanism that mediates glioma cell migration and invasion (11). Ephrin B2 and EphB4 were found to be overexpressed by endothelial cells of human malignant gliomas (12). EphrinB3 was demonstrated as an important factor regulating glioma cell invasion through Rac1 (13). The EphA2 protein was overexpressed in the GBM and anaplastic astrocytoma tissues and was identified as a novel target for the development of glioma vaccines (14). Recently, it was also demonstrated that the EphA2 receptor is highly overexpressed in GBM in comparison to normal brain tissue and possesses important oncogenic properties (15).

Although several previous reports implicated EphA2 in glioma pathogenesis (14-16), its prognostic value for primary and recurrent GBM has not yet to be demonstrated. In the present study, we investigated the immunohistochemical expression of EphA2 and identified this receptor as a new potential diagnostic and prognostic marker for further Eph/ephrin-targeted molecular cancer therapy in GBM when correlated with clinical pathological parameters and tumor vascularity. The association of the tumor microvessel density (MVD) with several clinical pathological parameters and overall survival was also investigated.

\section{Materials and methods}

Forty samples of 32 patients with histologically-confirmed GBM, WHO grade IV, (26 primary GBM and 14 recurrent GBMs, including eight pairs of the same patients) and 10 normal brain samples were obtained from the University Hospital of Marburg, Germany. Their usage was approved by the Ethics Committee of the Philipps-University Marburg and all patients gave their informed consent prior to surgery. The patients underwent surgery and received postoperative radiation therapy and combined chemotherapy with ACNU and VM-26. The first follow-up occurred 6 weeks after therapy was completed. Subsequent follow-ups were scheduled every three months. In addition to the clinical investigations and monitoring of the indices of recurrence, a radiological examination was undertaken to detect possible relapses. Disease progression was defined (according to WHO criteria) by either an increase of at least $25 \%$ in tumor size or any new tumor identified by CT or MRI scan (2). Normal brains which included the cortex and white matter, without any evidence of brain tumor or other brain disease, five cases of male and five cases of female (age ranging from 27 to 70 years, average 48.6 years) were obtained from autopsy cases.

Immunohistochemistry. Immunohistochemical studies were performed on formalin-fixed, paraffin-embedded tissue. Sample slides were passed through a sequence of Roti-histol (Carl Roth, Karlsruhe, Germany) and graded alcohol and then rinsed in phosphate-buffered saline (PBS). After rinsing with PBS, the slides were treated with $3 \%$ hydrogen peroxide in PBS for $15 \mathrm{~min}$ at room temperature in order to eliminate endogenous peroxidase activity. Subsequently, the slides were treated with $5 \%$ blocking serum for $1 \mathrm{~h}$. Following this, the slides were incubated overnight at $4{ }^{\circ} \mathrm{C}$ with a rabbit antihuman EphA2 polyclonal antibody (1:100 dilution; Santa Cruz Biotechonology, Heidelberg, Germany), or rabbit antihuman Factor VIII (von Willebrand factor, vWF) polyclonal antibody (1:400 dilution; Dako Cytomation, Carpinteria, CA). In the negative controls, the primary antibody was replaced with $1 \mathrm{x}$ PBS. The signal was enhanced by using biotinylated polyclonal goat anti-rabbit IgG for $30 \mathrm{~min}$ and incubated with streptavidin-HRP (Dako Cytomation) for $30 \mathrm{~min}$. The colour was developed after a $5 \mathrm{~min}$ incubation with 3,3-diaminobenzidine (DAB) solution and the sections were weakly counterstained with hematoxylin for $10 \mathrm{sec}$.

Evaluation of EphA2 expression. The membranous and cytoplasmic expression of EphA2 on tumor cells was assessed at a $\times 400$ magnification. The assigned score first reflected the staining intensity A ( 0 , negative; 1 , weak; 2 , moderate; 3 , high) and second the percentage of positive cells B ( 0 , no positive cells; $1,<25 \%$ positive cells; 2,25 to $50 \%$ positive cells; 3 , $>50 \%$ positive cells). An overall score of 3 was defined as positive staining. The score of the EphA2 expression was scored using a scale between 0 and 3 (negative, low, moderate and high, respectively). The scoring was performed separately by two independent observers who were not informed about the clinical data. Any discrepancies in the scores were resolved on the conference microscope.

Evaluation of MVD at the 'hot spot' of tumor angiogenesis. Tumor angiogenesis can be reflected by MVD in the most vascularised areas of tumor tissue. MVD, as highlighted by factor VIII-related antigen immunostaining, was assessed without knowledge of the patient clinical outcome, as described by Weidner et al (17). Briefly, each slide was scanned at low magnification (x100) to identify the four areas with the highest density of microvessel (hot-spots). Each hot-spot was then evaluated at high power magnification (x200) for the number of stained microvessels per field in a $0.7386 \mathrm{~mm}^{2}$ surface area. vWF-positive stained blood vessels with a complete lumen as well as cell clusters without luminae were considered as individual microvessels. The final microvessel score was the average of the vessel counts from the four fields assessed by a high power magnification field (x200).

Statistical analysis. Survival curves were estimated using the Kaplan-Meier method. The distributions of survival were compared using the log-rank test. The Chi-square test was employed to determine the association between EphA2 expression intensity on tumor and epithelial cells and MVD. A p-value $<0.05$ was considered to be statistically significant. All statistical analyses were performed using SPSS software.

\section{Results}

Thirty-two patients with histologically-confirmed primary and recurrent GBM and WHO grade IV were studied. The mean age at diagnosis was 54.3 years (range 31-71). No significant difference in age distribution between males (21 cases) and females (11 cases) was determined. All 32 patients showed a relapse between 1 and 22 months after 

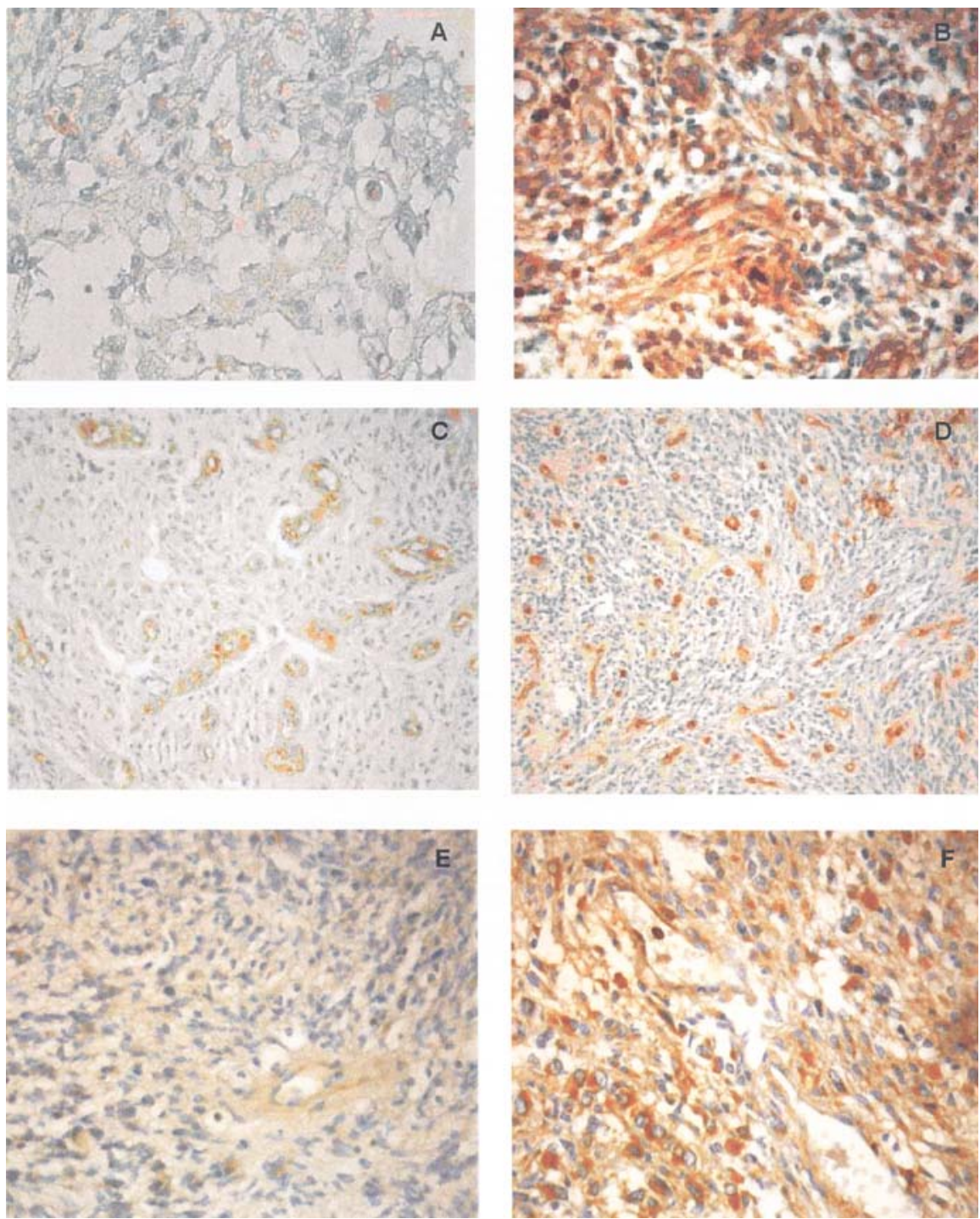

Figure 1. Immunohistochemical demonstration of the EphA2 protein expression and blood vessels in GBM. Representative examples of GBM showing weak positive staining in tumor cells (A) or strong membranous and cytoplasmic staining in both tumor and endothelial cells (B). Microvessel density in GBM by immunohistochemical staining for $\mathrm{vWF}$, microvessels are represented by brown clusters which stand out sharply from other tissues (C and D). A low-tumor vascularity (C) in GBM with a low expression of EphA2 is shown in A. In contrast, the microvessel density was relatively high in GBM with a high expression of EphA2 as shown in B. A different expression of EphA2 in paired primary and recurrent GBM, a weak positive staining in the tumor and endothelial cells of primary GBM (E) and a strong staining in the tumor and endothelial cells of recurrent GBM (F); original magnification, x400 (A, B, E and F) and x200 (C and D).

Table I. The EphA2 expression and intratumor microvessel density in 40 specimens of 32 primary and recurrent GBM.

EphA2 expression
Low and High p-value
moderate

\begin{tabular}{lccc}
\hline MVD & & & \\
Low & 11 & 9 & ns \\
High & 5 & 15 & \\
Tumor status & & & \\
Primary & 8 & 18 & ns \\
Recurrent & 8 & 6 & \\
\hline
\end{tabular}

ns, not significant; MVD, microvessel density. surgery and subsequently died of the disease (median survival 15 months).

The EphA2 immunoreactivity was observed in the membranes and cytoplasm of tumor cells as well as tumorassociated endothelial cells (Fig. 1A and B), but not in the 10 normal brain tissues analyzed. Furthermore, an increased expression of EphA2 was found in the high vascular bed tumor areas as well as in the endothelial cells around the tumor areas. Of the 40 GBM analyzed, all tumors showed positive staining for the EpA2 protein of different intensities. A strong expression of EphA2 was observed in $24(60 \%)$ of the GBM. The median MVD served as a cutpoint for the 30 vessels. A high MVD was noted in those areas where the overexpression of EphA2 was marked (Fig. 1C and D). However, there was no significant correlation between the expression of EphA2 and MVD $(\mathrm{p}>0.05$, Table I). Additionally, no significant correlation was detected between the expression levels of EphA2 or MVD and 
Table II. Relationship between the EphA2 expression or microvessel density and clinicopathological features of 32 patients with GBM.

\begin{tabular}{|c|c|c|c|c|c|c|}
\hline \multirow[b]{2}{*}{ Age } & \multicolumn{2}{|c|}{ EphA2 expression } & \multirow[t]{2}{*}{ p-value } & \multicolumn{2}{|c|}{ MVD } & \multirow[t]{2}{*}{ p-value } \\
\hline & $\begin{array}{l}\text { Low and } \\
\text { moderate }\end{array}$ & High & & Low & High & \\
\hline$\leq 50$ & 5 & 5 & & 4 & 6 & \\
\hline$>50$ & 8 & 14 & ns & 6 & 16 & ns \\
\hline \multicolumn{7}{|l|}{ Gender } \\
\hline Male & 11 & 10 & & 5 & 5 & \\
\hline Female & 2 & 9 & ns & 10 & 12 & ns \\
\hline
\end{tabular}

ns, not significant; MVD, microvessel density.
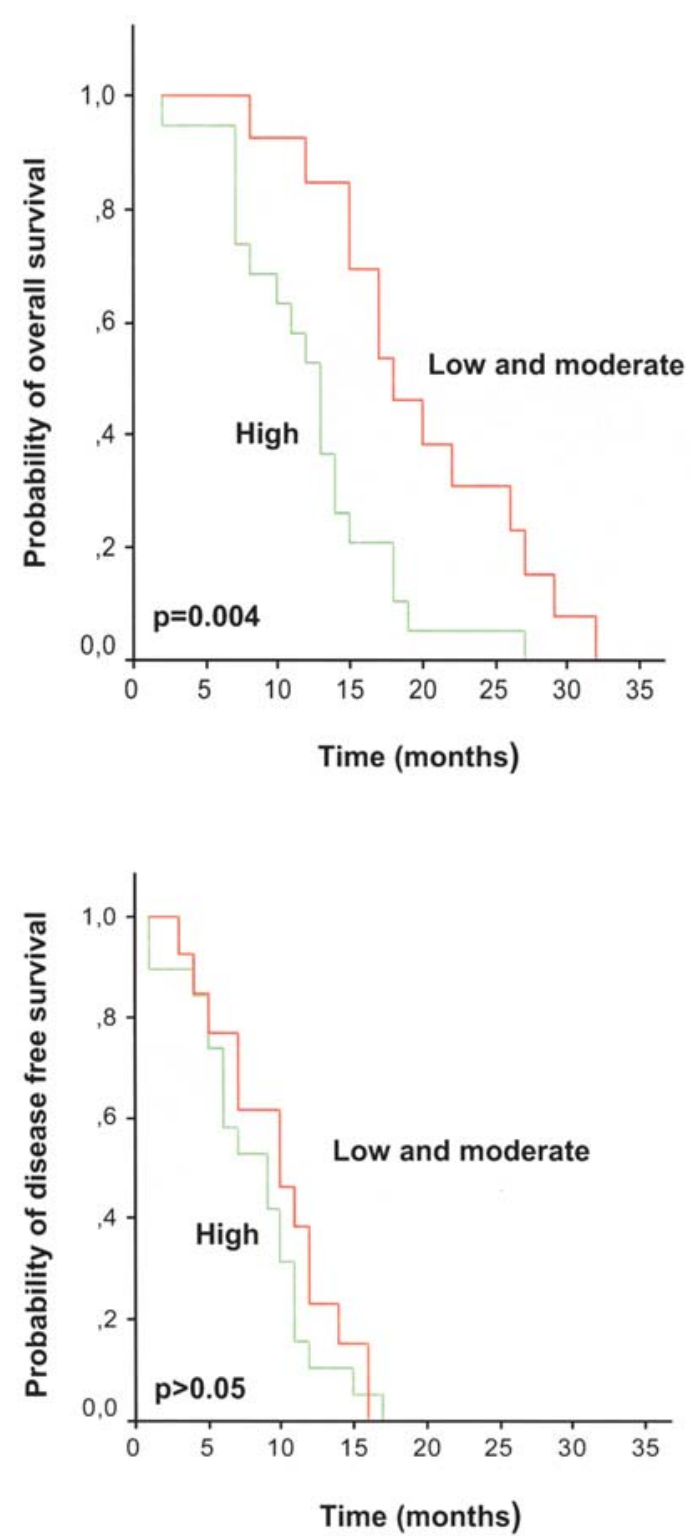

Figure 2. Kaplan-Meier curve for overall survival (A) and recurrence-free survival (B) in 32 patients based on a high or low EphA2 expression. An increased EphA2 expression was significantly associated with dead of disease ( $\mathrm{p}=0.004$ by log-rank test), when low and moderate expressing tumors (score $<3$ ) were plotted against high expressing tumors (score 3 ). clinical pathological parameters such as age and gender (Table II). Of the eight GBM with the primary and recurrent samples analyzed, an increased expression of EphA2 has been detected in 3 recurrent tumors (score: high expression) as compared to primary tumors (score: low or moderate expression, Fig. 1E and F). However, no statistically significant difference of the EphA2 expression was obtained between the primary and recurrent GBM (Table I).

The EphA2 protein expression showed an inverse correlation with the overall survival of GBM patients. Patients with a low/moderate expression of EphA2 (score $<3$ ) revealed a median survival of 18 months as compared to 12 months for patients with a high EphA2 expression (score 3, p=0.004). No association was noted between recurrence-free survival and EphA2 immunoreactivity ( $p>0.05$, Fig. 2). There was no correlation between MVD, recurrence-free and overall survival ( $p>0.05$, data not shown).

\section{Discussion}

Accumulating evidence indicates that a high expression of EphA2 has been associated with an increased potential for tumorigenicity, tumor growth and metastasis (4-6). The oncogenic functions of EphA2 can contribute to multiple aspects of the malignant character and were found to correlate with tumor stage and tumor progression $(18,19)$. The expression of EphA2 has been studied in various types of cancers, including prostate, lung, esophageal, melanoma, ovarian, cervical, breast, gastric and colorectal (20-28). Furthermore, the overexpression of EphA2 in esophageal, melanoma, ovarian and cervical cancers has been found to be strongly linked to cancer progression and metastasis and associated with the adverse clinical outcome of patients $(22-25,28)$. However, the functions and roles of EphA2 in brain tumor genesis had not been intensively studied previously. In the present study, we demonstrated the EphA2 immunoreactivity in both primary and recurrent GBM and a high level of EphA2 expression acted as a predictor for the unfavorable outcome of patients. These findings are in line with two recent studies on the expression and functions of EphA2 in human gliomas. Hatano et al found a restricted expression of EphA2 in 9 primary GBM (16). Using 
genome-wide screening, Liu et al identified that the overexpression of EphA2, as a mitogen, is associated with the inverse survival of the 21 primary GBM analyzed (15). In contrast, one additional functional study demonstrated an increased expression of EphA2 in $90 \%$ of 14 GBM and the inhibitory effect of EphA2 activation on the anchorageindependent growth and invasiveness of GBM cells (14). This reported discrepancy may reflect on the diverse functions of EphA2 under different conditions $(5,6)$. The present data are consistent with the fact that a positive correlation is emerging between the levels of expression of EphA2 and the observed degree of various malignant tumors (22-24). EphA2 seems to be functionally important in GBM cells and thus may play an important role in GBM pathogenesis as well $(14,15)$.

The process of angiogenesis plays a central role in local tumor growth and the development of distant metastases by facilitating the entry of cells into the circulation (19,30-32). Recently, rapidly accumulating evidence has suggested a critical role of Eph/ephrin signaling in angiogenesis (29). In addition to the vascular endothelial growth factor (VEGF) and Tie2 receptors, which have long been recognized as key angiogenic receptor tyrosine kinases, Eph receptors have now been identified as pivotal regulators of angiogenesis $(30,31)$. EphA2 is an essential regulator of endothelial cell assembly and migration in post-natal angiogenesis and EphA2deficient endothelial cells fail to assemble in vivo when transplanted into recipient mice (32). Notably, the expression of EphA2 was not reported in normal adult vasculature but seems to be widely up-regulated during tumor-associated angiogenesis $(19,32)$. In light of these reports, EphA2 may have a role both within the tumor cell and in the surrounding tumor microenvironment. In the current study, we found an increased expression of EphA2 in high vascular bed tumor areas as well as in the endothelial cells around tumor areas. Tumor angiogenesis can be measured histologically by MVD, which has been shown to be an independent parameter for malignant characteristics and prognosis of various types of cancers including gliomas (33-35). However, other studies suggested that the quantification of MVD has a limited prognostic value in GMB because of exuberant neovascularization in $\operatorname{GBM}(36,37)$. We agreed with the latter observations and could not illustrate a statistically significant correlation between the expression of EphA2 and MVD index.

The EphA2 receptor is a key determinant of malignant behavior in several different tumor types. The treatment of EphA2-Fc soluble receptors inhibits tumor angiogenesis and VEGF-dependent multi-stage carcinogenesis $(32,38,39)$. The internalization of the receptor with an agonist-antibody has been shown to decrease tumor volume and vascular density (41). The targeting of EphA2 by siRNA in pancreatic adenocarcinoma cells suppressed the invasion and migration of tumor cells and their formation in vivo (41) as well as tumor invasiveness $(42,43)$. Blocking the EphA2 receptor using an agonistic antibody reduced angiogenesis and tumor growth in an orthotopic ovarian cancer mouse model (44). Taken together, EphA2 may be a potential therapeutic target for anti-tumorigenic and anti-angiogenic therapies. The data in this study indicated that EphA2 may be a valuable candidate as a prognostic marker and a new targeted therapeutic assessment in primary and recurrent GBM. Additional experimental studies are necessary to unveil the biological pathway linking Eph/ephrins with tumor growth in cancer cells and tumor-associated vessels of GBM. Ultimately, the association of a strong EphA2 expression with the adverse outcome of GBM patients may lead to a novel screening test for tyrosine kinase inhibitor therapy.

\section{Acknowledgements}

We are very grateful to our technicians, Mrs B. Kleb, H. Geissel and R. Wassmuth for their expert technical assistance.

\section{References}

1. Ohgaki H and Kleihues P: Population-based studies on incidence, survival rates and genetic alterations in astrocytic and oligodendroglial gliomas. J Neuropathol Exp Neurol 64: 479-489, 2005.

2. Reifenberger G and Collins VP: Pathology and molecular genetics of astrocytic gliomas. J Mol Med 82: 656-670, 2004.

3. Zhu Y and Parada LF: The molecular and genetic basis of neurological tumors. Nat Rev Cancer 2: 616-626, 2002.

4. Pasquale EB: Eph receptor signaling casts a wide net on cell behaviour. Nat Rev Mol Cell Biol 6: 462-475, 2005.

5. Holland SJ, Gale NW, Mbamalu G, Yancopoulos GD, Henkemeyer $\mathrm{M}$ and Pawson $\mathrm{T}$ : Bi-directional signaling through the Eph-family receptor Nuk and its transmembrane ligands. Nature 383: 722-725, 1996

6. Davis S, Gale NW, Aldrich TH, Maisonpierre PC, Lhotak V, Pawson T, Goldfarb M and Yancopoulos GD: Ligands for Ephrelated receptor tyrosine kinases that require membrane attachment or clustering for activity. Science 266: 816-819, 1994.

7. Holder N and Klein R: Eph receptors and ephrins: effectors of morphogenesis. Development 126: 2033-2044, 1999.

8. Kullander K and Klein R: Mechanisms and functions of Eph and ephrin signaling. Nat Rev Mol Cell Biol 3: 475-486, 2002.

9. Bundesen LQ, Scheel TA, Bregman BS and Kromer LF: Ephrin-B2 and EphB2 regulation of astrocyte-meningeal fibroblast interactions in response to spinal cord lesions in adult rats. J Neurosci 23: 7789-7800, 2003.

10. Nakada M, Niska JA, Tran NL, McDonough WS and Berens ME: EphB2/R-Ras signaling regulates glioma cell adhesion, growth and invasion. Am J Pathol 167: 565-576, 2005.

11. Nakada M, Niska JA, Miyamori H, McDonough WS, Wu J, Sato $\mathrm{H}$ and Berens ME: The phosphorylation of EphB2 receptor regulates migration and invasion of human glioma cells. Cancer Res 64: 3179-3185, 2004

12. Erber R, Eichelsbacher U, Powajbo V, Korn T, Djonov V, Lin J, Hammes HP, Grobholz R, Ullrich A and Vajkoczy P: EphB4 controls blood vascular morphogenesis during postnatal angiogenesis. EMBO 25: 628-641, 2006.

13. Nakada M, Drake KL, Nakada S, Niska JA and Berens ME: Ephrin-B3 ligand promotes glioma invasion through activation of Rac1. Cancer Res 66: 8492-8500, 2006.

14. Wykosky J, Gibo DM, Stanton C and Debinski W: EphA2 as a novel molecular marker and target in glioblastoma multiforme. Mol Cancer Res 3: 541-551, 2005.

15. Liu F, Park PJ, Lai W, Maher E, Chakravarti A, Durso L, Jiang X, Yu Y, Brosius A, Thomas M, Chin L, Brennan C, DePinho RA, Kohane I, Carroll RS, Black PM and Johnson MD: A genomewide screen reveals functional gene clusters in the cancer genome and identifies EphA2 as a mitogen in glioblastoma. Cancer Res 66: 10815-10823, 2006

16. Hatano M, Eguchi J, Tatsumi T, Kuwashima N, Dusak JE, Kinch MS, Pollack IF, Hamilton RL, Storkus WJ and Okada H: EphA2 as a glioma-associated antigen: a novel target for glioma vaccines. Neoplasia 7: 717-722, 2005.

17. Weidner N, Semple JP, Welch WR and Folkman J: Tumor angiogenesis and metastasis-correlation in invasive breast carcinoma. N Engl J Med 324: 1-8, 1991.

18. Brantley-Sieders D and Chen J: Eph receptor tyrosine kinases in angiogenesis: from development to disease. Angiogenesis 7: $17-28,2004$ 
19. Ogawa K, Pasqualini R, Lindberg RA, Kain R, Freeman AL and Pasquale EB: The ephrin-A1 ligand and its receptor, EphA2, are expressed during tumor neovascularization. Oncogene 19: 6043-6052, 2000.

20. Walker-Daniels J, Coffman K, Azimi M, Rhim JS, Bostwick DG, Snyder P, Kerns BJ, Waters DJ and Kinch MS: Overexpression of the EphA2 tyrosine kinase in prostate cancer. Prostate 41: 275-280, 1999.

21. Kinch MS, Moore MB and Harpole DH Jr: Predictive value of the EphA2 receptor tyrosine kinase in lung cancer recurrence and survival. Clin Cancer Res 9: 613-618, 2003.

22. Miyazaki T, Kato H, Fukuchi M, Nakajima M and Kuwano H: EphA2 overexpression correlates with poor prognosis in the esophogeal squamous cell carcinoma. Int J Cancer 103: 657-663, 2003.

23. Easty DJ, Hill SP, Hsu MY, Fallowfield ME, Florenes VA, Herlyn $M$ and Bennett DC: Up-regulation of ephrin-A1 during melanoma progression. Int J Cancer 84: 494-501, 1999.

24. Thaker PH, Deavers M, Celestino J, Thornton A, Fletcher MS Landen CN, Kinch MS, Kiener PA and Sood AK: EphA2 expression is associated with aggressive features in ovarian carcinoma. Clin Cancer Res 10: 5145-5150, 2004.

25. Wu D, Suo Z, Kristensen GB, Li S, Troen G, Holm R and Nesland JM: Prognostic value of EphA2 and EphrinA-1 in squamous cell cervical carcinoma. Gynecol Oncol 94: 312-319, 2004.

26. Zelinski DP, Zantek ND, Stewart JC, Irizarry AR and Kinch MS: EphA2 overexpression causes tumorigenesis of mammary epithelial cells. Cancer Res 61: 2301-2306, 2001.

27. Nakamura R, Kataoka H, Sato N, Kanamori M, Ihara M, Igarashi H, Ravshanov S, Wang YJ, Li ZY, Shimamura T, Kobayashi T, Konno H, Shinmura K, Tanaka M and Sugimura H: EPHA2/EFNA1 expression in human gastric cancer. Cancer Sci 96: 42-47, 2005.

28. Kataoka H, Igarashi H, Kanamori M, Ihara M, Wang JD, Wang YJ, Li ZY, Shimaura T, Kobayashi T, Maruyama K, Nakamura T, Arai H, et al: Correlation of EphA2 overexpression with high microvessel count in human primary colorectal cancer. Cancer Sci 95: 136-141, 2004.

29. Heroult M, Schaffner F and Augustin HG: Eph receptor and ephrin ligand-mediated interactions during angiogenesis and tumor progression. Exp Cell Res 312: 642-650, 2006.

30. Gale NW and Yancopoulos GD: Growth factors acting via endothelial cell specific receptor tyrosine kinases: VEGFs, angiopoietins and ephrins in vascular development. Genes Dev 13: 1055-1066, 1999.

31. Yancopoulos GD, Davis S, Gale NW, Rudge JS, Wiegand SJ and Holash J: Vascular-specific growth factors and blood vessel formation. Nature 407: 242-248, 2000.

32. Brantley DM, Cheng N, Thompson EJ, Lin Q, Brekken RA, Thorpe PE, Muraoka RS, Cerretti DP, Pozzi A, Jackson D, Lin C and Chen J: Soluble Eph A receptors inhibit tumor angiogenesis and progression in vivo. Oncogene 21: 7011-7026, 2002.
33. Mitra AP, Datar RH and Cote RJ: Molecular pathways in invasive bladder cancer: new insights into mechanisms, progression and target identification. J Clin Oncol 24: 5552-5564, 2006 .

34. Chantrain CF, DeClerck YA, Groshen S and McNamara G: Computerized quantification of tissue vascularization using highresolution slide scanning of whole tumor sections. J Histochem Cytochem 51: 151-158, 2003.

35. Uzzan B, Nicolas P, Cucherat M and Perret GY: Microvessel density as a prognostic factor in women with breast cancer: a systematic review of the literature and meta-analysis. Cancer Res 64: 2941-2955, 2004

36. Yao Y, Kubota T, Takeuchi $\mathrm{H}$ and Sato K: Prognostic significance of microvessel density determined by an antiCD105/endoglin monoclonal antibody in astrocytic tumors: Comparison with an anti-CD31 monoclonal antibody. Neuropathology 25: 200-206, 2005.

37. Folkerth RD: Descriptive analysis and quantification of angiogenesis in human brain tumors. J Neurooncol 50: 165-172, 2000 .

38. Cheng N, Brantley D, Fang WB, Liu H, Fanslow W, Cerretti DP, Bussell KN, Reith A, Jackson D and Chen J: Inhibition of VEGF-dependent multi-stage carcinogenesis by soluble EphA receptors. Neoplasia 5: 445-456, 2003.

39. Cheng N, Brantley DM, Liu H, Lin Q, Enriquez M, Gale N, Yancopoulos G, Cerretti DP, Daniel TO and Chen J: Blockade of EphA receptor tyrosine kinase activation inhibits VEGFinduced angiogenesis. Mol Cancer Res 1: 2-11, 2002.

40. Carles-Kinch K, Kilpatrick KE, Stewart JC and Kinch MS: Antibody targeting of the EphA2 tyrosine kinase inhibits malignant cell behavior. Cancer Res 62: 2840-2847, 2002.

41. Duxbury MS, Ito H, Zinner MJ, Ashley SW and Whang EE: EphA2: a determinant of malignant cellular behavior and a potential therapeutic target in pancreatic adenocarcinoma. Oncogene 23: 1448-1456, 2004.

42. Duxbury MS, Ito H, Zinner MJ, Ashley SW and Whang EE: Ligation of EphA2 by ephrin-A1-Fc inhibits pancreatic adenocarcinoma cellular invasiveness. Biochem Biophys Res Commun 320: 1096-1102, 2004.

43. Walker-Daniels J, Riese DJ and Kinch MS: c-Cbl-dependent EphA2 protein degradation is induced by ligand binding. Mol Cancer Res 1: 79-87, 2002.

44. Landen CN, Lu C, Han LY, Coffman KT, Bruckheimer E, Halder J, Mangala LS, Merritt WM, Lin YG, Gao C, Schmandt R, Kamat AA, et al: Efficacy and antivascular effects of EphA2 reduction with an agonistic antibody in ovarian cancer. J Natl Cancer Inst 98: 1558-1570, 2006. 